\title{
Monitoring the Quality of Heating Oils and their Blends by Different Physical Methods
}

\author{
Rashed M.S.1, Katalin Kerti², , Vozáry E. ${ }^{2}$, Kovacs Z. ${ }^{2}$ \& Zeke I. ${ }^{2}$, Felföldi J. ${ }^{2}$ \\ (1) Food Science and Technology Dept., Fac. of Agric. Alexandria University, 21545, \\ El-Shatby, Alexandria, Egypt. \\ (2) Faculty of Food Science, Szent Istvan University, 1118 Budapest, Hungary.
}

Received: 8 May, 2019

Revised: 7 June, 2019

Accepted: 29 June, 2019

\begin{abstract}
The repeated usage of heating oils has been proven hazardous due to the degradation process by chemical reactions that lead to changes in the quality of the oil. There are numerous analytical methods which are capable of monitoring the quality deterioration in heating oils due to their repeated heating in deep fat frying processes. This work explores the effect of heating on the physical behaviour of soybean and rapeseed oils and their blends. Colour measurements, electrical impedance and differential scanning calorimetry (DSC) were used for monitoring the changes in oils and their blends due to the heating process. The results revealed that all methods are able to respond to the oil changes due to the heating process with different levels of accuracy. It was obvious that, colour measurements represented a high level of standard deviation. Electrical impedance showed its ability to be a candidate as a rapid monitoring method. Also, DSC was able to follow small changes in oils along with heating. Further tests are required to confirm the efficacy of the aforementioned methods using more oil blends to generalize the results..
\end{abstract}

Keywords: Frying oils, physical methods, electrical impedance, differential scanning calorimetry.

\section{INTRODUCTION}

Due to their unique flavour and texture, fried foods are consumed throughout the world. The conditions of frying $\left(160-180^{\circ} \mathrm{C}\right.$, air and moisture) result in deterioration of oil quality via complex of chemical reactions (oxidation, hydrolysis and polymerization) and such oils should be discarded, (Innawong et al., 2004). It is worth to mention that darkening of exhausted oils is a good indicator to prevent the continual use of such oils (Nayak et al., 2016). Differential scanning calorimetry (DSC) provides information on the excess specific heat over a wide range of temperatures. Any endothermic or exothermic event is registered as a peak in the chart, and its area is proportional to the enthalpy gained or lost, respectively. Another advantage of DSC, besides the small sample size, is that the oil content may be accessed directly in the fried product, avoiding extraction with solvents. In the same context; the application of a monochromatic voltage signal at the single frequency to sample results in a current of the same frequency. If the sample does not have capacitance and inductance, the phase of the current is the same as that of the voltage. However, if the sample has any capacitive reactance, a phase shift occurs.
As a result of the aforementioned methods used for monitoring changes in heated oils, the aim of the present work was to monitor the response behaviour of these methods. Moreover, accuracy of such methods was investigated as rapid monitoring methods based on the change of the physical characteristics of heated oils during the heating process.

\section{MATERIALS AND METHODS}

\section{Sample preparation}

Two types of oil collected from the local markets of Budapest, Hungary were examined. These oils are classified according to the level of unsaturation as follows: Rapeseed oil (Monounsaturated) and soybean oil (Polyunsaturated). Rapeseed oil was used for improving oleic acid content in the blends prepared for the experiment. Oil samples were kept in the refrigerator at around $6^{\circ} \mathrm{C} \pm 1^{\circ} \mathrm{C}$ and withdrawn at the time of the analysis. High oleic frying oil blends were tested at different ratios of rapeseed oil and soybean oil namely, 0:100, 25:75, 50:50, 75:25 and 100:0, respectively. Each sample was tested in 4 to 6 replicates to ensure the statistical reliability. 


\section{Heating process}

An amount of $1.8 \mathrm{~kg}$ oil was placed out in a $3 \mathrm{~L}$ capacity electric deep fat fryer and heated to $180 \pm 5$ ${ }^{\circ} \mathrm{C}$. Heating experiment was carried out for $6 \mathrm{hr}$ and samples were taken at $1 \mathrm{hr}$ intervals after the oil reached $180^{\circ} \mathrm{C}$. In order to determine the effect of heating on oil properties, samples $(\sim 300 \mathrm{ml})$ were taken at the end of the batch and kept at $6 \pm 1^{\circ} \mathrm{C}$ for physical analysis.

\section{Colour measurements}

Colour of oil samples was measured by Colour Lite Sph850 spectrophotometer coupled with CA10-LS adapter used for liquid samples. The instrument was calibrated to measure liquid CA10 mode; the number of the scans was adjusted to $3 \mathrm{cy}-$ cles and the final result was calculated as an average of 3 scans. Calibration was carried out by filling a disposal cuvette with double distilled water without any bubbles and placed in the holder. $\mathrm{L}^{*}, \mathrm{a}^{*}$, and $b^{*}$ values were measured. The measurements were in the whole spectrum of visible light, starting from $400 \mathrm{~nm}$ to $700 \mathrm{~nm}$. At the end of measurements, the data were exported to PC through the RS2312 interface and represented in excel spreadsheet.

\section{Differential scanning calorimetry (DSC)}

Thermophysical properties of samples were determined by a DSC 131 evo (Setaram Instrumentation, Caluire, France) differential scanning calorimeter and an immersion cooler (Flexi-Cool FC100, FTS, USA). Nitrogen (Messer Hungarogáz Kft., Budapest, Hungary) was used as the purge gas at a flow rate of $50 \mathrm{~cm}^{3} / \mathrm{min}$. A threestep calibration was used consisting of empty DSC pan, mercury, and indium. Samples of 20-25 mg were weighed, and an empty aluminum DSC pan was used as a reference. The temperature program was as follows: cooling from $+10^{\circ} \mathrm{C}$ to $-60^{\circ} \mathrm{C}$ by a cooling rate of $1{ }^{\circ} \mathrm{C} / \mathrm{min}$, then keeping at $-60^{\circ} \mathrm{C}$ for $10 \mathrm{~min}$. Sample temperature $\left(\mathrm{T},{ }^{\circ} \mathrm{C}\right)$ and heat flow $(\mathrm{H}, \mathrm{mW})$ were recorded. The data collection and analyses were controlled by Callisto Processing 1.076 software (AKTS AG, Siders, Switzerland). Crystallization peak temperature $\left(\mathrm{T},{ }^{\circ} \mathrm{C}\right)$ and latent heat of crystallization (peak area, $\Delta \mathrm{H}$, $\mathrm{J} / \mathrm{g}$ ) were measured using the cooling interval of the curve and fitting linear baseline (Zhang et al., 2013) isothermal crystallization kinetics studied by pulsed Nuclear Magnetic Resonance (pNMR).

\section{Electrical impedance measurements}

Electrical impedance measurements were carried out at room temperature for all the samples using two precision LCR meters HP4284A and HP 4285A in frequency ranges from $20 \mathrm{~Hz}$ up to $1 \mathrm{MHz}$ and from $75 \mathrm{kHz}$ up to $30 \mathrm{MHz}$, respectively. Ten $\mathrm{ml}$ of oil samples were placed in a $20 \mathrm{ml}$ plastic cuvette for measurement. Electrocardiograph electrodes (Fiab Spa) with a radius $6 \pm 0.04 \mathrm{~mm}$ were used in the measurements. The electrodes were immersed into the sample in form of a plane parallel with a distance between the electrodes $1.5 \pm 0.02 \mathrm{~mm}$. The applied electrical voltage was 1 volt. The magnitude, $|Z|$, and the phase angle, $\varphi$, of electrical impedance were determined. The real, $\mathrm{R}$ and the imaginary, $X$, part of impedance were calculated $R=|Z| \cos \varphi \quad X=|Z| \sin \varphi$ and were presented in the function of frequency. The effect of heating time on oils was illustrated with the spectrum of $\mathrm{R} / \mathrm{R}(5 \mathrm{kHz})$, the ratio of the real part and the real part at $5 \mathrm{kHz}$ frequency.

\section{Statistical Analysis}

Multivariate statistical analysis of the principal component analysis (PCA) was applied for evaluating results of electrical impedance measurements and it was performed by $\mathrm{R}$ project statistical software.

\section{RESULTS AND DISCUSSION}

\section{Colour measurements}

The colour of oils has been widely used as a subjective or objective index to determine the quality of the used oil. When oils are heated as in the frying process, they rapidly change from a light yellow to an orange-brown colour. This is the combined result of oxidation, polymerization and other chemical changes. These changes could be expressed as deviations in oil as $\mathrm{L}^{*}$, $\mathrm{a}^{*}$ and $\mathrm{b}^{*}$ values. The total colour difference (TCD), $\triangle \mathrm{E}$, which is a combination of parameters $\mathrm{L}^{*}, \mathrm{a}^{*}$ and $\mathrm{b}^{*}$ values, is a colorimetric parameter extensively used to characterize the variation of colour in foods during processing. It was calculated from the following equation: -

$$
\Delta E=\sqrt{(\Delta L)^{2}+(\Delta a)^{2}+(\Delta b)^{2}}
$$

Where, $L^{*}(100), a^{*}(0)$ and $b^{*}(0.05)$ refer to reference values, i.e. colour parameters of distilled 
water, and $\mathrm{L}^{*}, \mathrm{a}^{*}$ and $\mathrm{b}^{*}$ refer to colour values of the samples at various times during heating. An increase in TCD was observed in Fig. (1) with elongation of heating time. The ANOVA results of total colour difference (TCD) indicated that there are significant differences between oil along with heating time (Table 1).

The ANOVA results of colour component measurements showed that there are significant differences between oil mixtures in terms of $\mathrm{L}^{*}, \mathrm{a}^{*}$ and $b^{*}$ values. Regarding heating time, there was a significant difference for all $\mathrm{L}^{*}, \mathrm{a}^{*}$, and $\mathrm{b}^{*}$ values; Moreover, within these parameters, only a* showed an increase in its values on contrary to $L^{*}$ and $b^{*}$ showing decreasing patterns (Fig. 2). On the other hand, only $b^{*}$ values showed significant differences between samples in terms of different mixing level. These results are in accordance with the results obtained by Maskan, (2003).

As a result, the assumption of homogeneity of variances was violated, it is proposed to use GamesHowell posthoc test for evaluating the ability of the method for discriminating between oil according to their time of heating based on measuring $L^{*}$ value. The results showed that colour measurement is not capable of discriminating between oils at the short time; however, it is a suitable method for differen- tiating among them at longer heating times. Taking into consideration the standard deviation levels, the results showed the sensitivity of this method is very low as it shown in Fig. (3). The colour, measurement is not suitable to be the only method for discriminating heated oils. Therefore, the colour measurement could be one of the rapid parameters for evaluating discarding point of heating oil based on the decrease in their lightness values.

The ANOVA results (not shown) for the level of saturation and heating time with different wavelengths starting from $400 \mathrm{~nm}$ to $700 \mathrm{~nm}$ showed that there are significant differences between oil blends based on the level of unsaturation. The results indicated that the effective range for discriminating oils based on their heating time ranged between $400 \mathrm{~nm}$ to $530 \mathrm{~nm}$. Moreover, it showed that the wavelengths have the highest significances for discriminating oils based on their mixing levels and their heating time is $430 \mathrm{~nm}$. Therefore, the coupling between colour determinations with any other parameter could be much more accurate in judging the quality of heating oils.

\section{Differential scanning calorimetry (DSC)}

According to Aguilera \& Gloria (1997), the typical cooling curves of the fat shows a single exotherm, which occurs due to crystallization to the

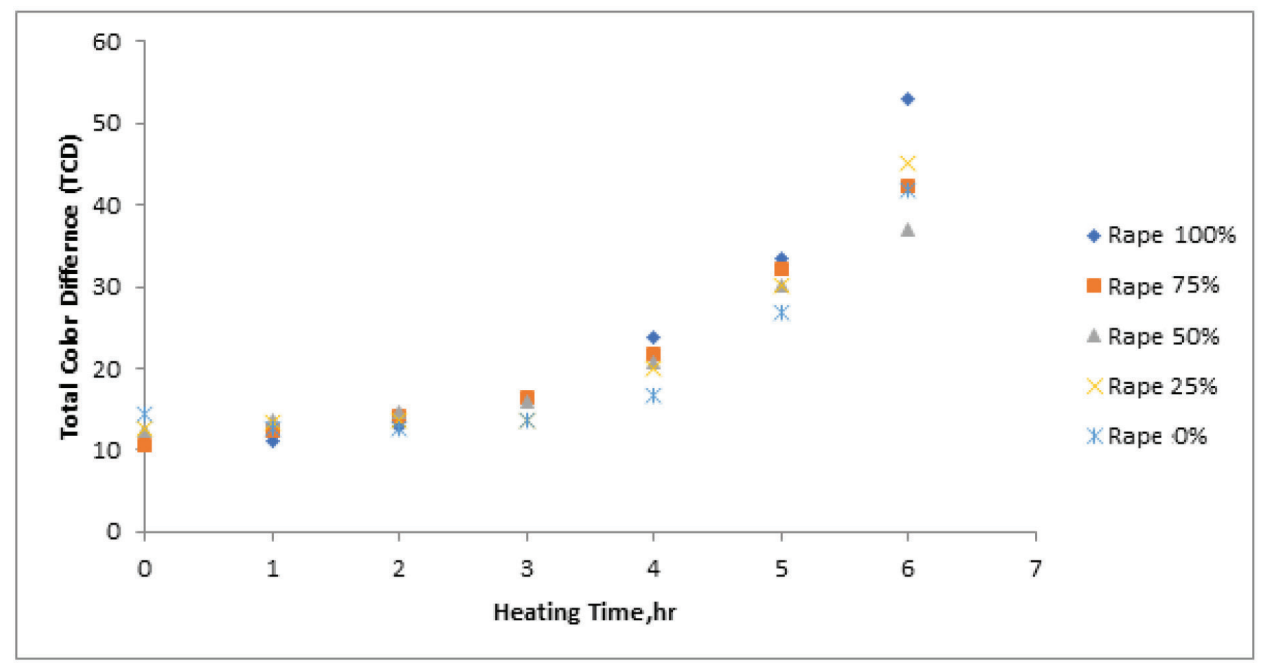

Fig 1: Effect of heating time on TCD values of all oil samples

Table 1. The ANOVA results of TCD values for oil blends as influenced by heating time

\begin{tabular}{lclcccc}
\hline Source of Variation & SS & df & MS & F & P-value & F $_{\text {Crit }}$ \\
\hline Within groups & 4240.516 & 6 & 706.7527 & 97.96948 & $1.12 \mathrm{E}-15$ & 2.508189 \\
Between groups & 40.14217 & 4 & 10.03554 & 1.391119 & 0.266883 & 2.776289 \\
Error & 173.1362 & 24 & 7.214009 & & & \\
\hline
\end{tabular}



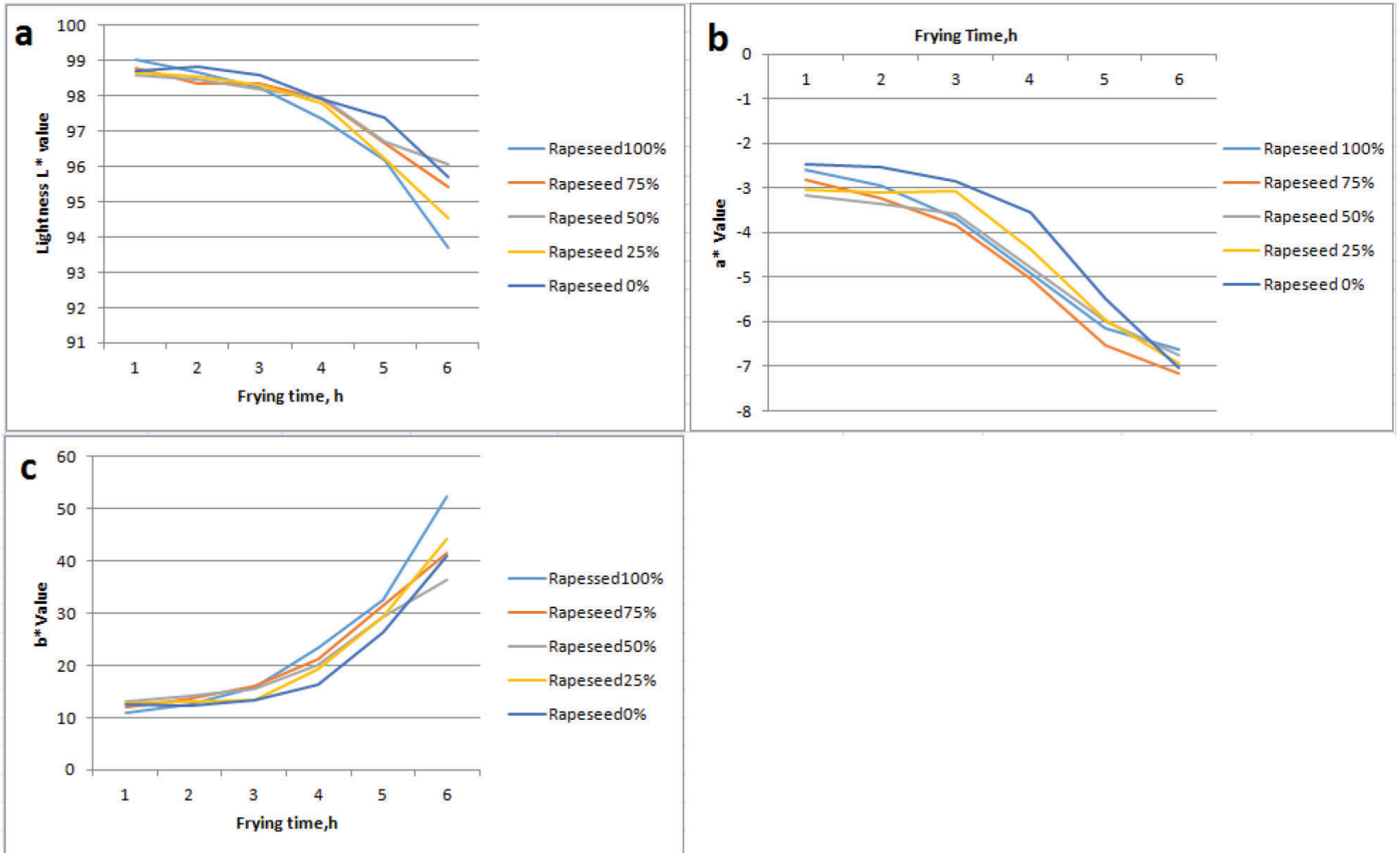

Fig.2: All colour measurement parameters;

A: $L^{*}$ values for different levels of saturation along with heating time;

B: $a^{*}$ values for different levels of saturation along with heating time;

$C: b^{*}$ values for different levels of saturation along with heating time.

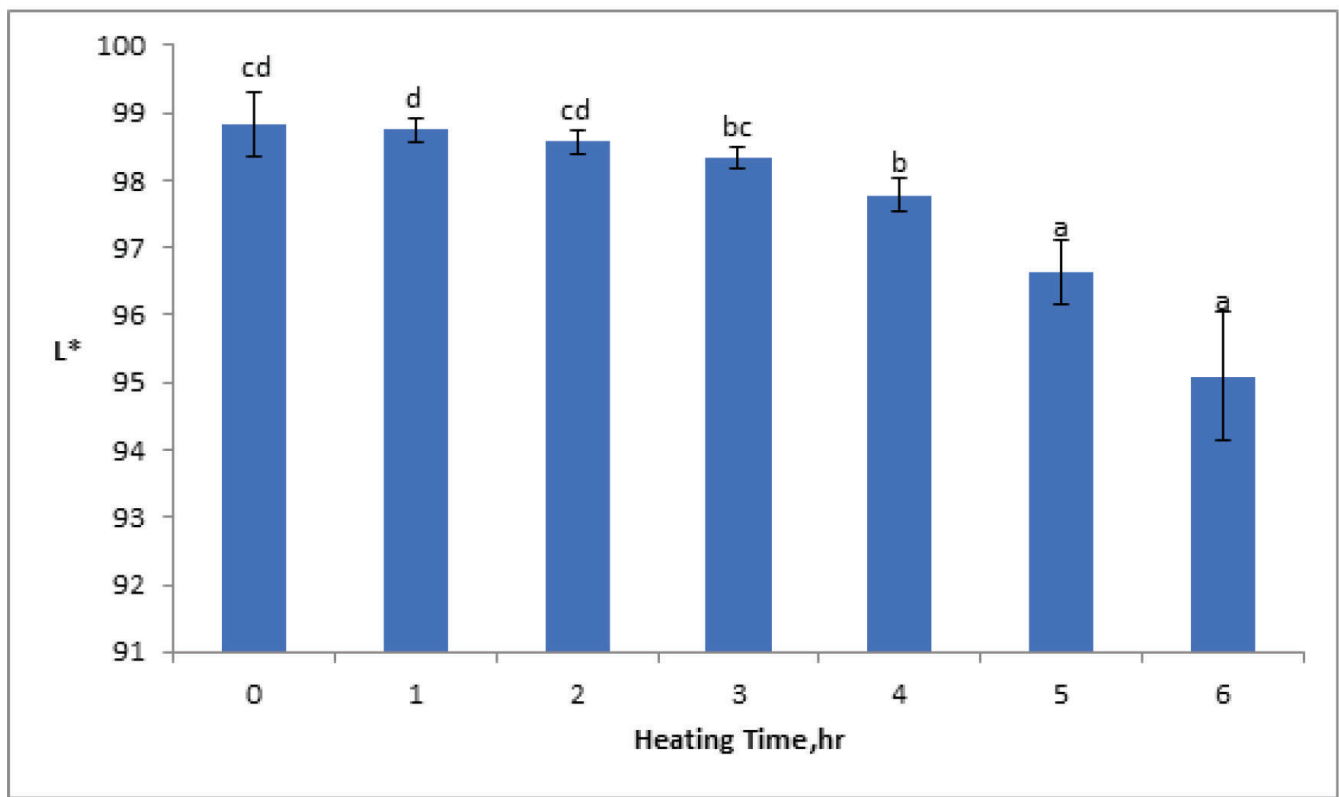

Fig. 3: Representation of standard deviation levels of $L^{*}$ values during heating process

least stable $\alpha$-form. The effect of heating time at $180^{\circ} \mathrm{C}$ on the thermal characteristics (value of peak and heat of crystallization) of rapeseed oil blends with soybean oil in different levels are represented in Table (2). Heat flow curves of the effect of heating time $(0,3$, and $6 \mathrm{~h})$ at $180^{\circ} \mathrm{C}$ on the crystalli- zation peak with different mixing levels between soybean oil and rapeseed oil are shown in Fig. (4).

It was clear that during heating of oils, the crystallization peaks tend to move towards lower temperatures and became broader with a dramatic 
Table 2. The effect of heating time on thermal characteristics of oil blends

\begin{tabular}{lll}
\hline Sample & \multicolumn{2}{c}{ Enthalpy, Peak Temperature, } \\
& H (J/g) & T $\left({ }^{\circ} \mathbf{C}\right)$ \\
\hline Rapeseed oil 25\% 0 h & -14.27 & -48.854 \\
Rapeseed oil 25\%3 h & -5.547 & -57.854 \\
Rapeseed oil 50\% 0 h & -21.274 & -46.255 \\
Rapeseed oil 50\% 3 h & -8.852 & -55.275 \\
Rapeseed oil 75\% 0 h & -30.854 & -42.8 \\
Rapeseed oil 75\% 3 h & -10.554 & -51.485 \\
Rapeseed oil 100\% 0 h & -31.757 & -41.533 \\
Rapeseed oil 100\% 3 h & -25.738 & -43.257 \\
Soybean oil 100\% 0 h & -21.467 & -52.689 \\
Soybean oil 100\% 1 h & -14.526 & -55.569 \\
Soybean oil 100\% 2 h & -4.281 & -57.902 \\
\hline
\end{tabular}

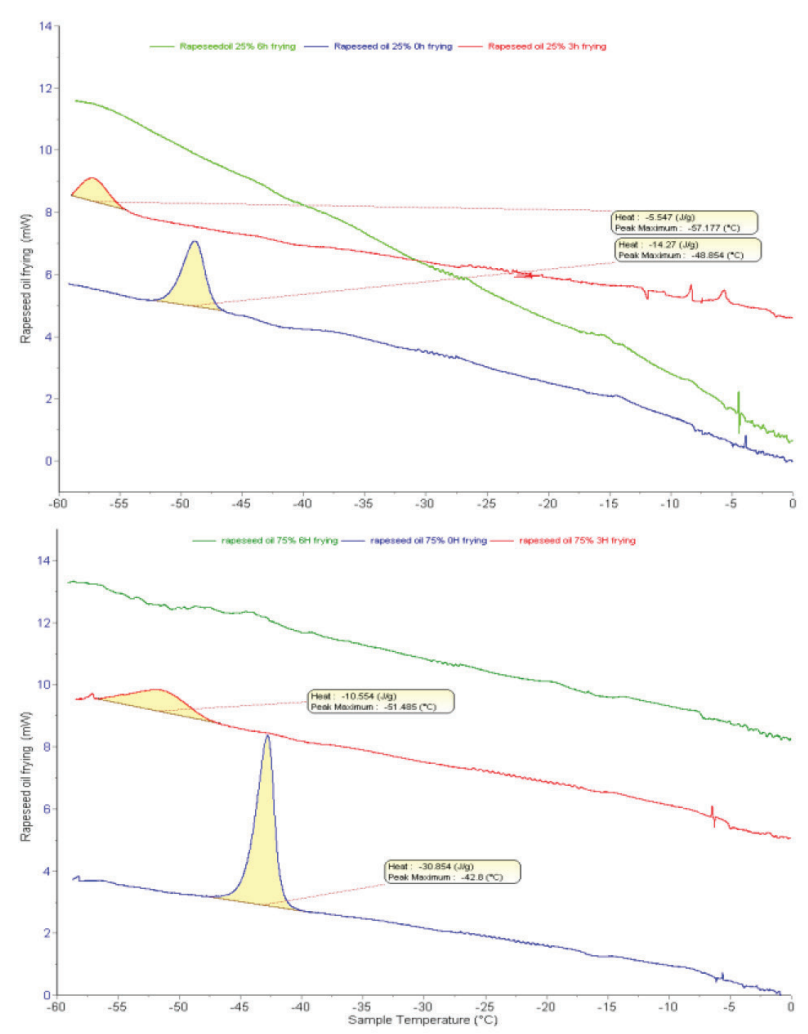

very likely assign to the fade of triacylglycerols and the formation of deterioration compounds that do not form crystals in the scanning temperature range. These assumptions have been reinforced by the results obtained from monitoring the crystallization of heated soybean oil. Fig. (5) shows the effect of heating time at $180^{\circ} \mathrm{C}$ on the crystallization peak of soybean oil. As it represented, increasing the level of unsaturation causes a great drop in enthalpy. moreover, the more unsaturation, the more formation of degradation products responsible for producing off-flavour of heating oils.

\section{Electrical impedance measurements}

The results of electrical magnitude and phase angle measurements of soybean oil before heating process are represented in Fig. (6). It was clear that there are differences between electrical impedance

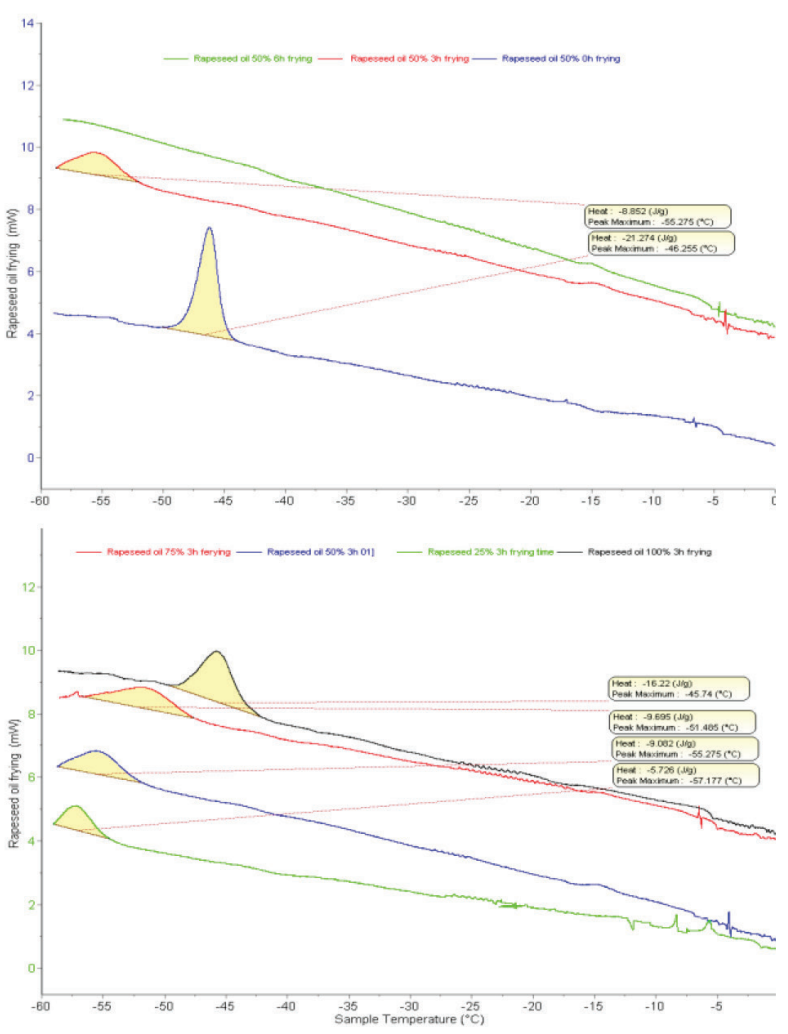

Fig. 4: Heat flow curves showing the effect of heating time on the crystallization peak of oil blends

decrease of the enthalpy. Man \& Swe (1995) investigated the effect of presence of oxidation products and found that partial glycerides and free fatty acids are responsible for these shifts to lower temperatures. In this on-going scenario, the aforementioned products are responsible for the resettlement in the crystallization peaks. The downsizing in the crystallization enthalpy along with heating time values during heating, especially at higher frequencies compared with low frequencies. Fig. (7) represents the ratios of electrical impedance decline of oil blends at different heating times. Frequency ranged between $5 \mathrm{kHz}$ and $5 \mathrm{MHz}$ being the most effective range for differentiating between heating times of oils.

Figure (8) shows the representation of a 


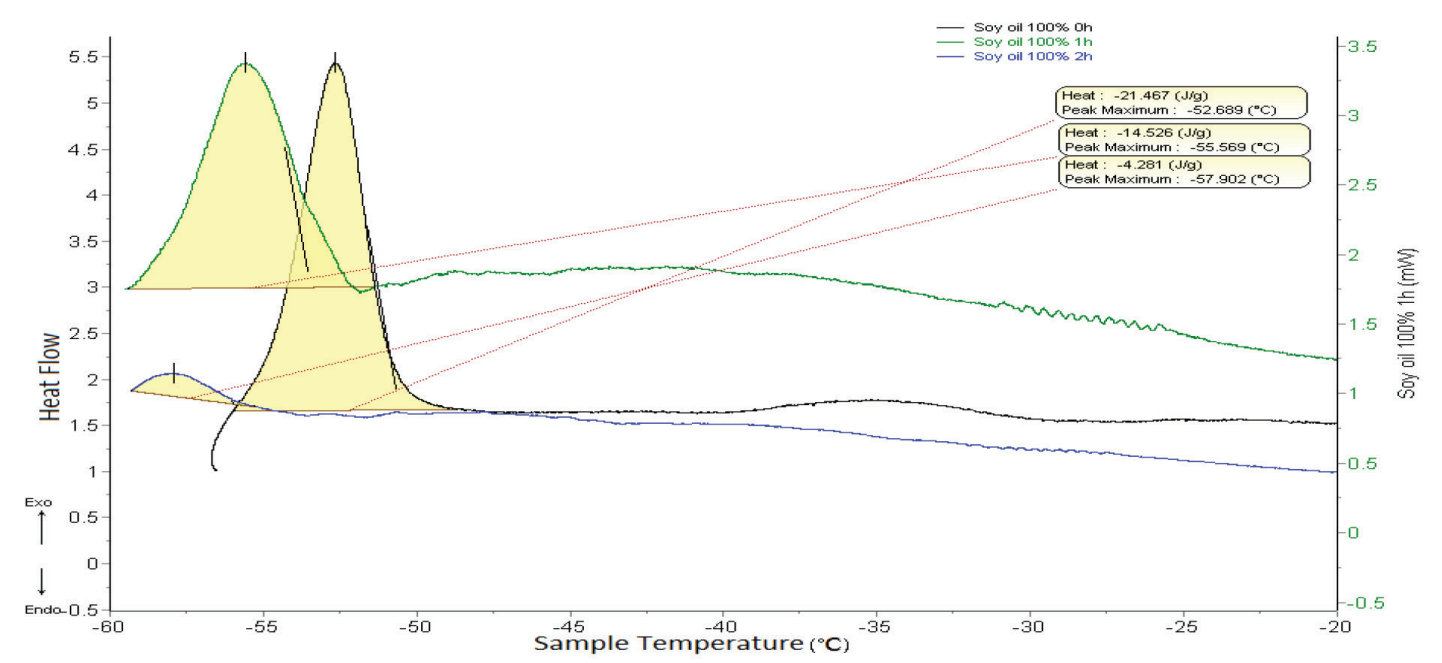

Fig. 5: Heat flow curves showing the effect of heating time on the crystallization peak of soybean oil

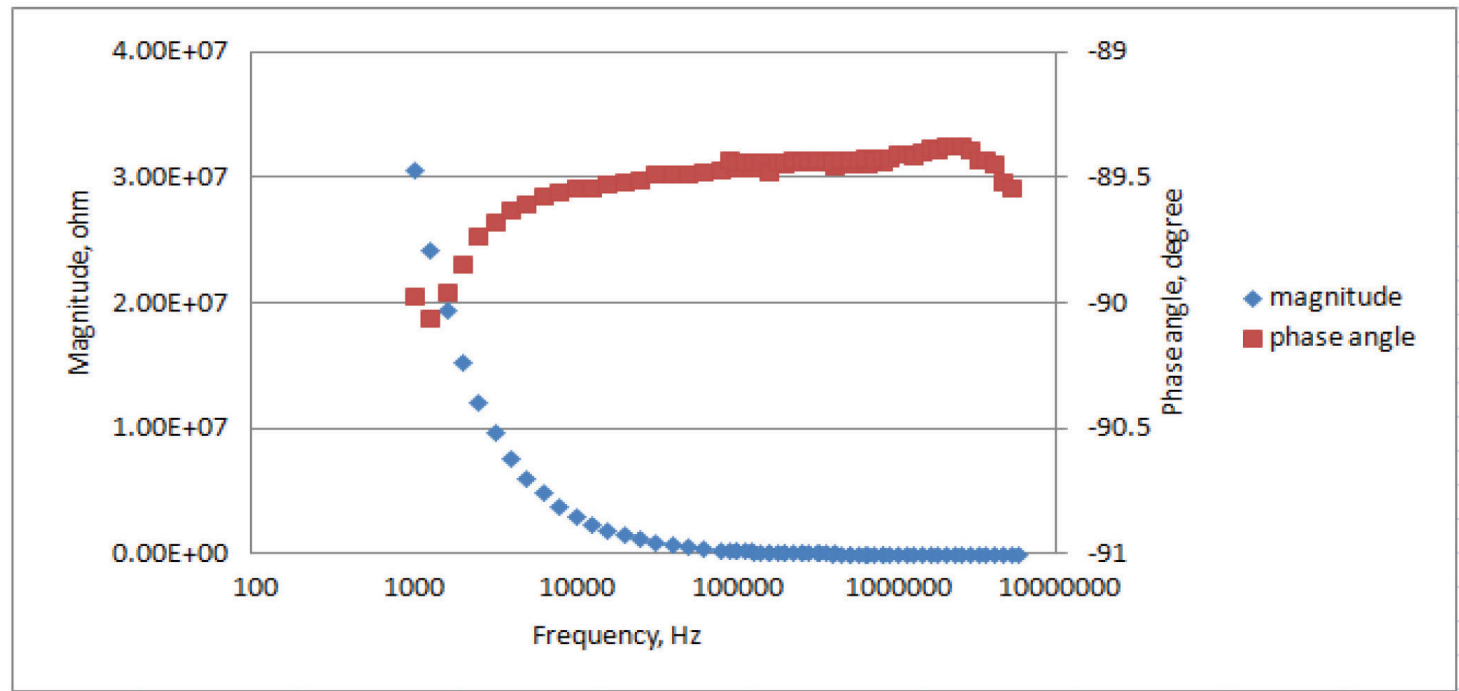

Fig. 6: Magnitude and phase angle of electrical impedance for soybean oil before heating

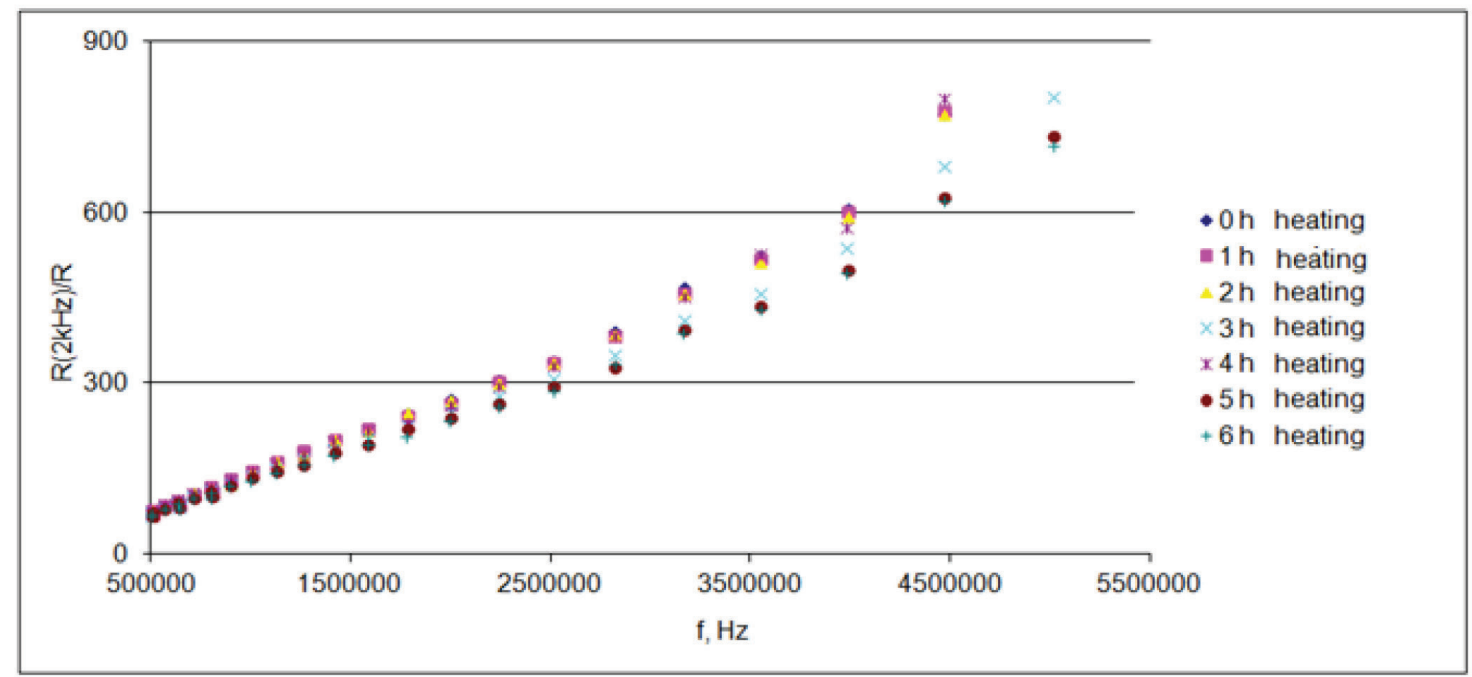

Fig. 7: Ratios of electrical impedance decline of soybean oil along with heating time. 
decline in electrical impedance of oil blends as heating time was elongated. Small differences could be traced among oil blends based on the ratio of the decline of their electrical impedance. These small differences could be as a result of short time frame for the experiment $(6 \mathrm{~h})$ compared with other researchers ( Sankarappa \& Prashantkumar, 2014, Luiz et al., 2015, Yahya et al., 2015), who conducted their experiments for a longer time, ranging between 30 and 40 $\mathrm{h}$. Moreover, as a result of general high electrical impedance for all oil blends, small values could not be neglected.

As a confirmation step for the previous results, representation of electrical impedance along with the full range of the spectrum principle component analysis (PCA) for both mixing level and the heating time was carried out. The results obtained from
PCA is illustrated in Fig. (9). It was obvious that electrical impedance is not able to discriminate among oil blends. Moreover, the ability for differentiating between heated oil is mainly influenced by the time of the treatment regardless of the mixing ratio of oils. These findings are in agreement with the results of Khaled and Aziz (2014).

\section{CONCLUSION}

The aim of the present study was to compare among different physical methods in its response towards changes in heated oils. It can be concluded that, from the results, the coupling between colour measurements with any other parameter may be much more accurate in judging the quality of heating oils. The measurements of electrical impedance along with DSC are promising techniques. However, the effect of the type of food, oil was not

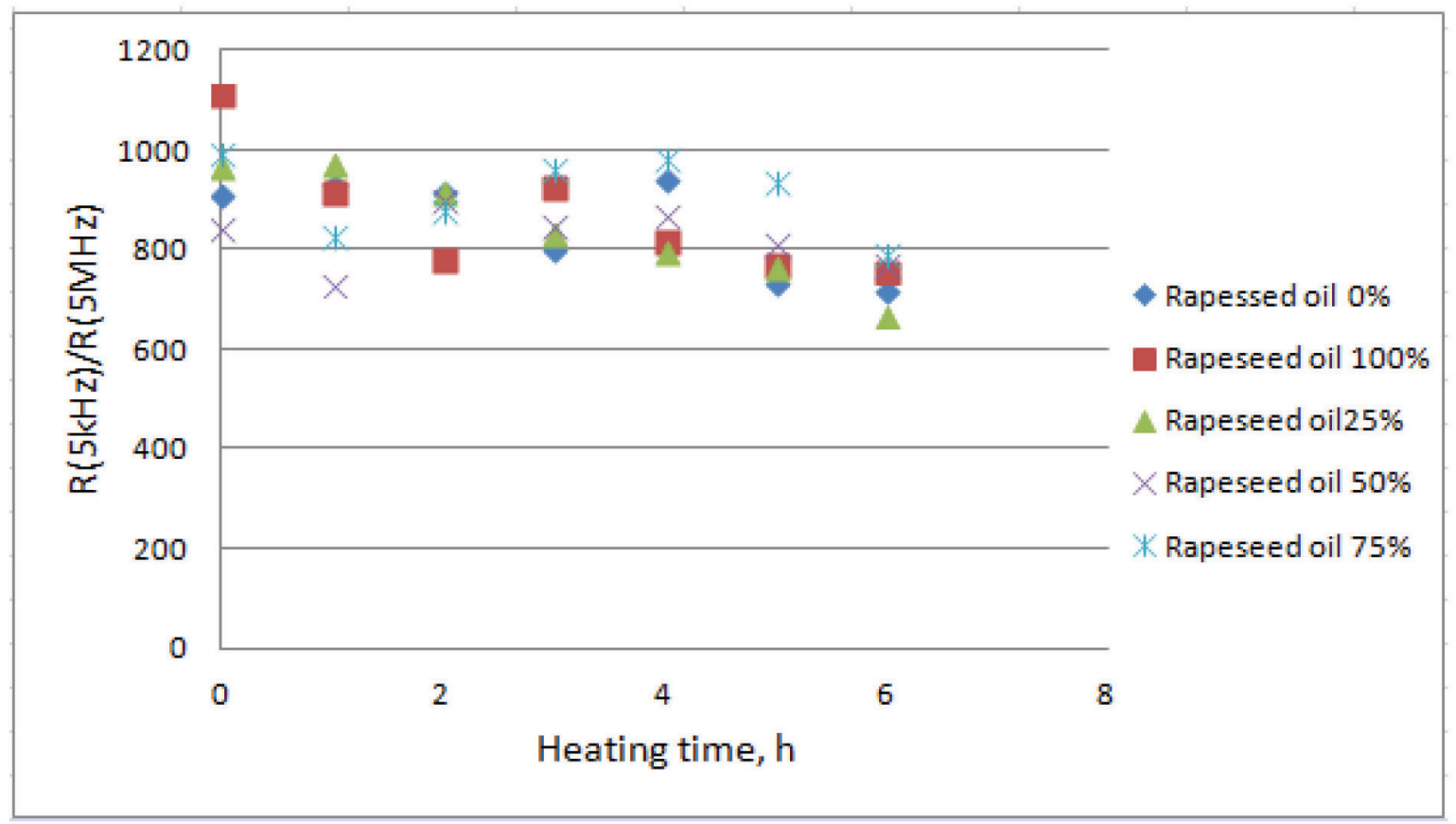

Fig. 8 : Decline of electrical impedance of oil blends along with heating time
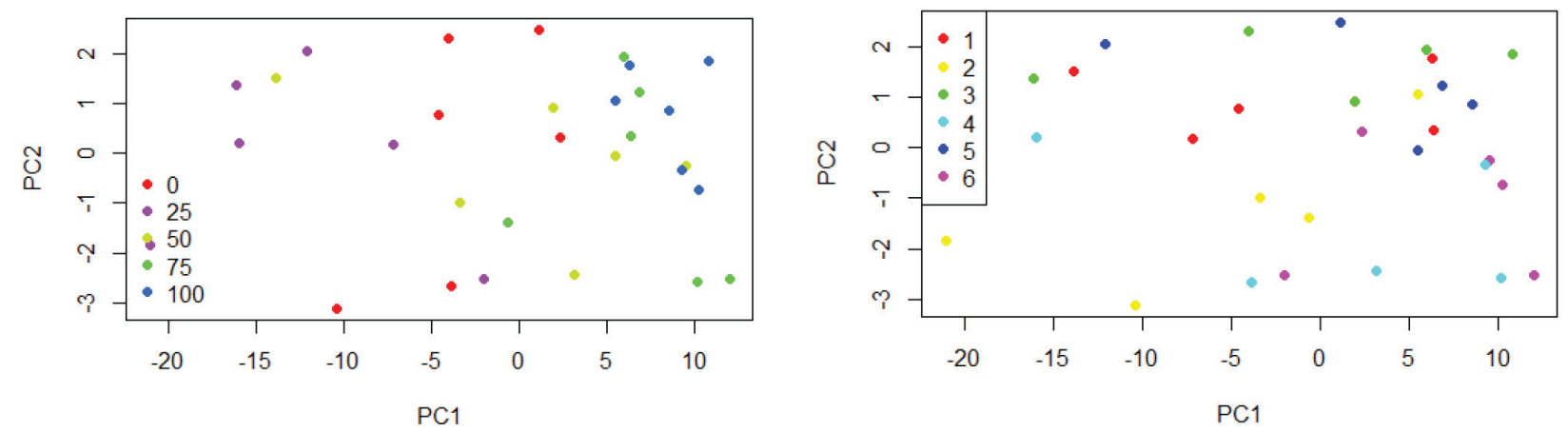

Fig. 9: The PCA components obtained from mixing levels and heating time 
investigated in the present study. So, all these results need further validations to explore the effect of food type on such results.

\section{REFERENCES}

Aguilera, J. M., \& Gloria, H. 1997. Determination of oil in fried potato products by differential scanning calorimetry. Journal of Agricultural and Food Chemistry, 3: 781-785.

Innawong, B., Mallikarjunan, P., Irudayaraj, J., \& Marcy, J. E. 2004. The determination of frying oil quality using fourier transform infrared attenuated total reflectance. LWT- Food Science and Technology, 37:23-28.

Khaled, A. Y., \& Aziz, S. A. 2014. Impedance sensor probe for degradation assessment of cooking oil. International Conference of Agricultural Engineering, Zurich, 6-10.

Luiz, S., Jr, S., Paiter, L., Galvão, J. R., Roque, D. V., \& Chaves, E. S. 2015. Sensor and Methodology for Dielectric Analysis of Vegetal Oils Submitted to Thermal Stress. Sensors, 26457-26477.

Man, Y. B. C., \& Swe, P. Z. 1995. Thermal analysis of failed-batch palm oil by differential scan- ning calorimetry. Journal of American Oil Society, 72:1529-1532.

Maskan, M. 2003. Change in colour and rheological behaviour of sunflower seed oil during frying and after adsorbent treatment of used oil. European Food Research Technolgies, 218: 20-25.

Nayak, P. K., Dash, U. M. A., Rayaguru, K., \& Krishnan, K. R. 2016. Physio-chemical changes during repeated frying of cooked oil: A Review.Journal of Food Biochemistry, 40:371-390.

Sankarappa, T., \& Prashantkumar, M. 2014. Dielectric properties and AC conductivity in some refined and unrefined edible oils. Journal of Agricultural and Food Chemistry, 1: 1-7.

Yahya, A., Abd, S., \& Zaman, F. 2015. Capacitive sensor probe to assess frying oil degradation. Information Processing in Agriculture, 2: 142-148.

Zhang, X., Li, L., Xie, H., Liang, Z., Su, J., Liu, G., \& Li, B. 2013. Comparative analysis of thermal behavior, isothermal crystallization kinetics and polymorphism of palm oil fractions. Molecules, 18: 1036-1052. 


\section{تتبع زيوت التسخين ومخاليطها بطرق فيزيائية مختلفة فئنة}

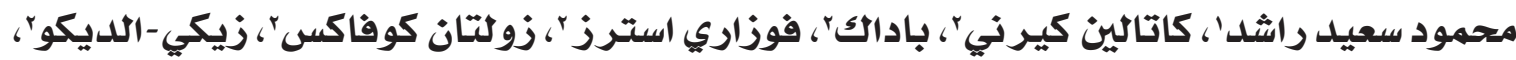
فلفولدي جوزيف باديف

ا - قسم علوم وتقنية الأغذية، كلية الزراعة، جامعة الإسكندرية، 10ک0 - الشاطبي، الإسكندرية r- كلية علوم الغذاء، جامعة سانت استفان - المجر

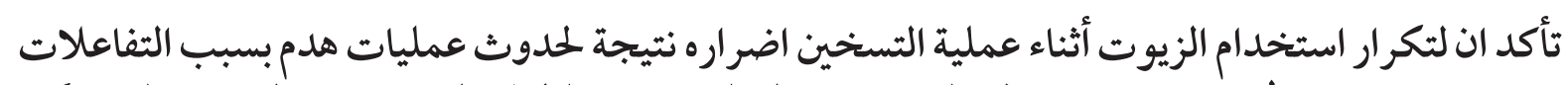

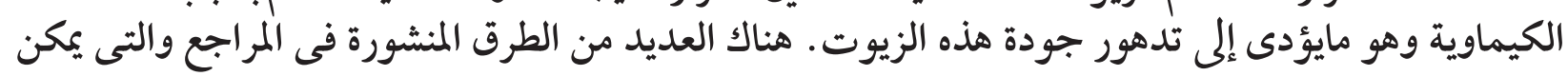

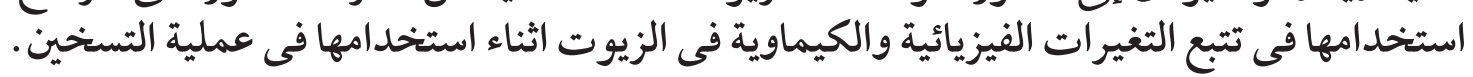

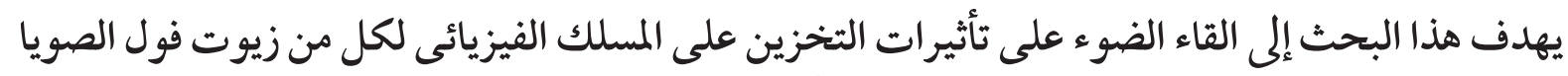

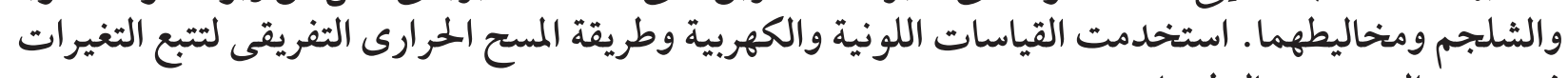
فى نوعى الزيت ومخحاليطهما.

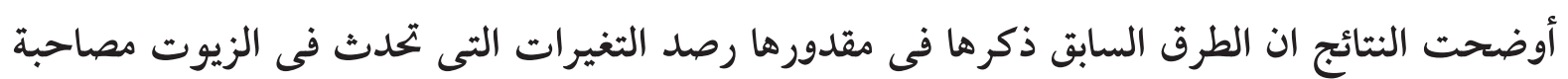

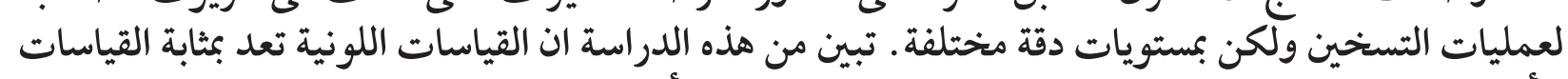

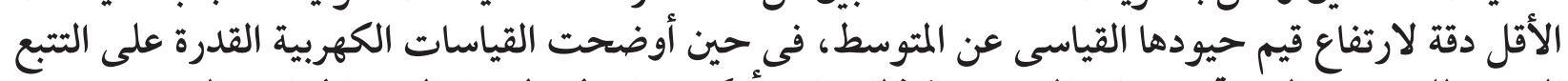

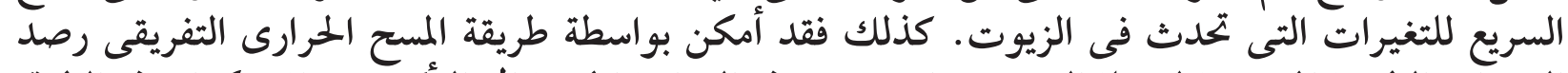

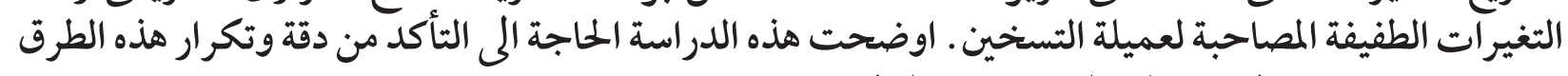

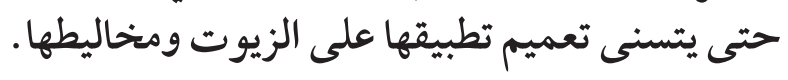


